\title{
Ateísmo y Laicismo: Nuevos horizontes para Chile
}

\author{
Manuel Contreras Seitz ${ }^{1}$ \\ Carlos Livacic Rojas ${ }^{2}$
}

\begin{abstract}
Resumen
En medio del desarrollo de una sociedad secularizada la discusión acerca del ateísmo y el laicismo vuelven a tomar importancia a la luz de los lentos cambios que evidencian las cifras acerca de la adscripción religiosa en Chile. Se propone discutir sobre los alcances del ateísmo y el laicismo en una sociedad en la que la mayoría opta por opciones religiosas al momento de ser consultados sobre su pertenencia religiosa.
\end{abstract}

Palabras clave: Laicismo, Ateísmo, Sociedad Secular, Adscripción Religiosa.

\begin{abstract}
In the midst of developing a secular society discussion about atheism and secularism resumed their importance in light of the slow changes that show the figures on religious affiliation in Chile. It is proposed to discuss the scope of atheism and secularism in a society in which most religious options to choose When surveyed about their religious affiliation.
\end{abstract}

Key words: Secularism, Atheism, Secular Society, Religious Affiliation

$1 \quad$ Universidad de Los Lagos. mcontrer@ulagos.cl

2 Universidad de Los Lagos. clivacic@ulagos.cl 
Ateísmo y Laicismo: Nuevos horizontes para Chile - Manuel Contreras Seitz y Carlos Livacic Rojas

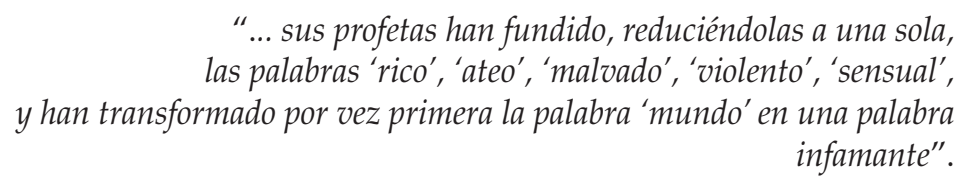

(Federico Nietzsche, Más allá del bien y del mal).

En Chile, la discusión sobre las religiones es un tema pendiente desde que la dictadura militar impusiera sus parámetros ideológicos -y por ende religiosos- para "librar a Chile del yugo marxista", lo que implicaba, naturalmente, "liberarlo" también de la profunda veta que se había venido instalando en el país respecto del análisis y la crítica de los modelos sociales, económicos y de pensamiento que se habían instalado. Ya en 1941, Alberto Hurtado reconocía que: "Es verdad que hay aún en la mayoría de nuestro pueblo un fondo de religiosidad que se manifiesta por el bautismo de los niños, por las imágenes que se conservan en las casas, y por algunas prácticas, muchas de ellas más supersticiosas que religiosas. La vida cristiana empero, se va debilitando casi hasta desaparecer en algunas regiones" (p.79).

En febrero de 1981, Raúl Silva Henríquez, señalaba en una entrevista efectuada en Punta de Tralca:

“- Existen gobernantes autoritarios que afirman defender valores "occidentales y cristianos" con su obra de gobierno.

- No. Ningún totalitarismo puede ser un modelo de vida cristiano. Dicen que son cristianos, pero no creemos que lo sean". (Ortega, 1981:348)

Rescato de estas expresiones la frase "Ningún totalitarismo puede ser un modelo de vida cristiano", que si bien es cierto se ha dicho en el contexto de los gobiernos autoritarios, encierra un trasfondo mayor, por lo que implica el concepto de totalitarismo, considerando que en un sentido lato, se refiere a aspectos mucho más amplios que el solo ejercicio patente del poder político -digo patente, pues también existe un ejercicio latente o subterráneo de este poder, que se manifiesta a través de ejes de influencia pre- 
parados ideológicamente- sino también de otros "poderes" que pretenden hacer sentir su peso en la conciencia, y por ende en el accionar, de las personas.

Como otro dato para iniciar la discusión, cabe señalar que el Censo de Población de 2002 arrojó resultados interesantes respecto de la caracterización religiosa de los chilenos:

El censo de 2002 consultó 9 opciones en la pregunta sobre religión, ampliando así el número de alternativas respecto a los censos anteriores. Los resultados obtenidos indican que el 70,0\% de los habitantes de quince años o más se declaró católico; el 15,1\% evangélico; el 4,4\% se identificó con otra religión o credo, y el 8,3\% dijo no tener religión, ser ateo o agnóstico. El censo de 1992 mostró que el 76,7\% de los habitantes de 14 años o más se declaró católico; el 12,4\% evangélico; el 0,8\% protestante; el 4,2\% se identificó con otra religión o credo y el 5,8\% dijo ser indiferente o ateo.

Cuadro 1: Distribución por sexo en cada religión.

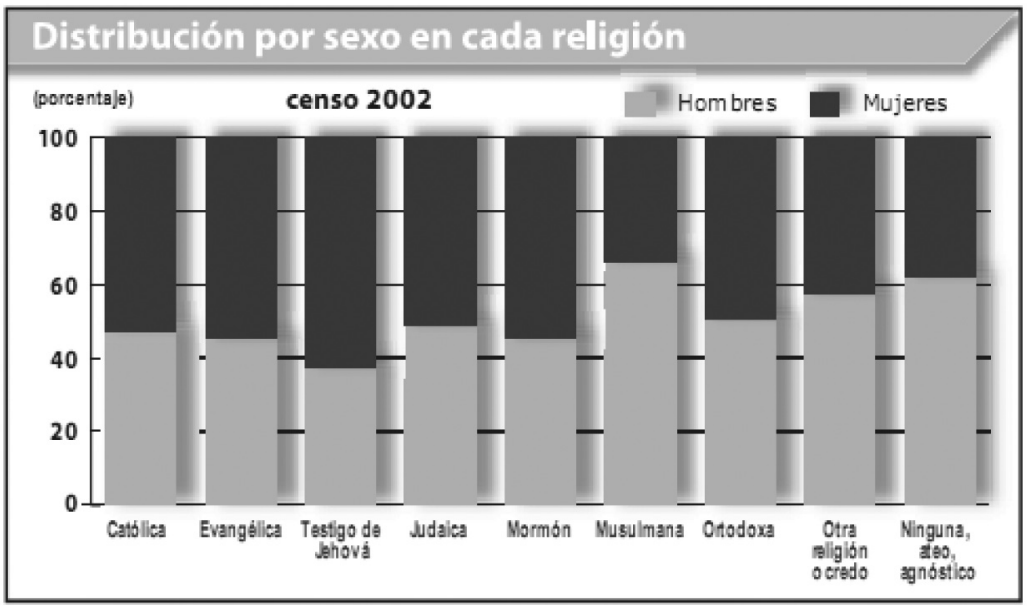

Fuente: Censo 2002, Instituto Nacional de Estadísticas.

Llama la atención la cifra respecto del catolicismo, sobre todo pensando que la propia Iglesia Católica había declarado que no 
Ateísmo y Laicismo: Nuevos horizontes para Chile - Manuel Contreras Seitz y Carlos Livacic Rojas

reconocería este parámetro si estaba bajo dicho guarismo y, más aún, considerando que -dada la propia experiencia- hubo censadores que se negaban sistemáticamente a marcar la opción de "no tener religión, ser ateo o agnóstico", instruyendo a quienes eran censados que bastaba con ser bautizado para declararse católico.

¿Qué sucede con este último parámetro? ¿Por qué el temor manifiesto de la Iglesia Católica al aumento sostenido de la manifestación abierta respecto de la opción laica? Trataremos de entregar algunas ideas para reflexionar respecto de este punto de vista.

La sola mención del concepto de ateísmo provoca un conjunto de reacciones, tanto positivas como negativas, que dependen de la actitud que el sujeto manifieste en torno a tal idea. Suele asociársela a algún tipo de conducta fuera de toda norma ética o moral, producto generalmente del vínculo -artificial- de moral con religión, cualquiera que ésta sea. Pero, ¿en qué consiste el ser ateo, o lo que es lo mismo, el modelo cognitivo del ateísmo?

En primer lugar, para aclarar algunos puntos que pueden prestarse a confusión, presentaré algunas distinciones que Drange (1998) entrega respecto de los conceptos de teísmo, ateísmo y agnosticismo. El autor propone, para situarnos en contexto, que respondamos las siguientes preguntas:

La oración Dios existe ¿expresa una proposición?

Si es así, entonces ¿la proposición es verdadera o falsa?

Al responder que no a la primera pregunta, tenemos una actitud no-cognitiva respecto de la posibilidad de hablar de Dios; si lo hacemos positivamente, expresamos al menos la posibilidad de conocimiento respecto de este tema. Para el autor, tanto teístas, ateos y agnósticos se ubican en este último grupo. ¿Cuáles son las diferencias entonces? El teísta responderá que la segunda pregunta es verdadera o puede serlo; el ateo, que dicha proposición es falsa o puede serlo y el agnóstico, si bien es cierto comprende la pregunta, se resiste a responderla pues "la evidencia es insuficiente". 
Esta primera clasificación parece bastante simple y suficiente para abarcar todo nuestro problema, sin embargo, sólo lo es en apariencia. ¿Por qué? Por la también simple razón que el concepto que sirve de base a la clasificación no es tal, ya que no está previamente definido y acotado. A manera de ejemplo, llenemos de contenido la expresión Dios existe y busquemos nuestra propia clasificación respecto de cada una de ellas:

Dios: el universo mismo, todo lo que existe.

Dios: el poder que ha creado el universo.

Dios: el creador omnipotente del universo cuyo gran objetivo respecto de los seres humanos es que crean que tuvo un hijo que murió por ellos para obtener su salvación.

Dios: ninguna definición es posible; la palabra es indefinible.

Si pensamos en Dios como en la primera dimensión, no queda otra salida que aceptar su existencia, puesto que evidentemente el universo existe; en los demás casos es posible la negación, cuyas consecuencias nos situarían como agnósticos, ateos o nocognitivistas, respectivamente.

Con todo, las concepciones más comunes sobre la divinidad nos sitúan dentro de las perspectivas $\boldsymbol{b}$. y $\boldsymbol{c}$., referidas básicamente a algún tipo de religión o manifestación religiosa, es decir, el ateísmo lo sería respecto de una concepción religiosa particular de Dios (el dios cristiano, judío, musulmán o, para otros casos, de algunos o todos los dioses del panteón sagrado de religiones como el hinduismo, panteísmo, u otras).

Sin embargo, la perspectiva que más réditos ha dado, y dentro de la cual muchas veces quienes nos sindicamos en esta postura también caemos, es la de aceptar, al menos en nuestra sociedad occidental, que la perspectiva del ateísmo involucra única y necesariamente la negación de la existencia del Dios de Israel, vale decir, la negación de la manifestación antropomórfica de la divinidad presente en la realidad musulmano-judeo-cristiana. Esta perspectiva, en todo caso, no resiste mayores análisis, ya que im- 
Ateísmo y Laicismo: Nuevos horizontes para Chile - Manuel Contreras Seitz y Carlos Livacic Rojas

plicaría, por lógica consecuencia, que aquellas personas que profesasen otra creencia religiosa, por ejemplo, fueran ateos, ya que reconocerían a otra divinidad como única, negando en tanto la posibilidad de la existencia de otra diferente, lo que convertiría, desde este punto de vista, a su vez en "ateos" a quienes profesaran algunas de las religiones judeo-cristianas, por citar un caso.

Entendemos, por tanto, que el ateísmo es una postura que trasunta las religiones, aun cuando podamos estar en presencia de una postura débil y una fuerte, entendiendo la primera como la manifestación de "no creer en Dios alguno", mientras que la segunda señala, más nietzscheanamente, que "Dios no existe" (o como dice el filósofo alemán, 'Dios ha muerto, bailemos sobre su tumba').

Quienes comúnmente nos identificamos como ateos lo hacemos dentro de la postura conocida como 'débil', vale decir, aquella que no circunscribe la trascendencia del ser humano a la regularización y enclaustramiento de religión alguna, pero que admite la posibilidad de conocimiento más allá de los límites de la materialidad y de la naturaleza. La segunda, en tanto, puede derivar hacia la presunción que lo único existente es el mundo material y que éste se encuentra gobernado por leyes, todas ellas predecibles. Detrás de esta aseveración se halla, por cierto, la negación del espíritu, de la trascendencia, de cualquier fuerza vital, etc.

A pesar de la secularización y progresiva laicización de la sociedad, en particular de nuestra sociedad chilena, el ateísmo es una postura que aún cuesta mucho manifestar, por cuanto conlleva un estereotipo social, negativo por supuesto, que relaciona al individuo ateo con graves carencias sociales y morales. A este punto es que nos referiremos a continuación.

"Pero, entonces, ¿cuál es el papel del Estado en lo que toca a la búsqueda de un sabio equilibrio, en beneficio de la conciencia individual y del fuero interno? Este papel consiste en permitir a quienes son más débiles, menos numerosos o mal aceptados, el gozo de tal libertad. En 
otros términos, el Estado actúa como un árbitro, que no toma partido por una determinada concepción de la vida, pero que actúa de tal forma que ninguna persona pueda imponer la suya a los otros" (Haarscher, El Laicismo).

Según datos aportados por Richard Scheinin (1993), "cuando se trata de mentir en currículums laborales, hacer trampa en los exámenes o plagiar reportes, la gente que se considera a sí misma como devotos asistentes a la misa, suele dejar su ética en la puerta de la capilla cuando vuelven a sus casas y trabajos... De hecho /... / la conducta ética de las personas que dicen que la religión es esencial en sus vidas no se suele distinguir de aquellas que la describen como poco importante".

Esta perspectiva se encuentra en la base de la discusión que nos permitiremos plantear y dejar esbozada en este punto: la falacia de que la moral religiosa es la única aceptable para la interrelación entre los individuos que forman una sociedad, descartando otras alternativas, como la posibilidad de una "moral atea".

Sin embargo, cuando indagamos en los conceptos generalmente aceptados acerca del sentido del término, encontramos que no hay implicancias religiosas en ello, al menos contemporáneamente, ya que puede ser considerado como lo "perteneciente o relativo a las acciones o caracteres de las personas, desde el punto de vista de la bondad o malicia" (adj.) o como la "ciencia que trata del bien en general, y de las acciones humanas en orden a su bondad o malicia" (DRAE, s.v. "moral"). Entonces, ¿qué hace que se asuma como intrínsecamente verdadero el que la religión sea la que proporcione las normas que regirán a toda la comunidad social?

Como veíamos, los datos del Censo 2002 en Chile arrojan algunas luces sobre tendencias manifiestas en el tiempo. De la población de 15 años o mayor a esa edad, un 8,3\% se declaró ateo o agnósticos (931.990 personas). Entre ellas, un 62,4\% son hombres 
Ateísmo y Laicismo: Nuevos horizontes para Chile - Manuel Contreras Seitz y Carlos Livacic Rojas

(581.546) y un 37,6\% son mujeres (350.444). Más aún, un desglose por edades nos indica que, entre los 15 y 29 años hay 407.644 chilenos que admiten esta opción de vida (3,63\% del total nacional; 43,74\% de la opción) y, entre 30 y 44, se manifiestan 301.395 personas (2,68 de la población total y un 32,34\% de la opción). Esto indica claramente que, con el paso del tiempo y de no pocas circunstancias históricas, la sociedad, especialmente las nuevas generaciones, asigna un espacio importante a la discusión lúcida de conceptos que eran considerados universales e inamovibles.

Por otra parte, si indagamos un poco más a fondo dentro de los grandes principios o "mandamientos" religiosos, podremos darnos cuenta que, salvo aquellos tocantes a la divinidad, los relativos a la sociedad sólo formalizan conceptos generales y de bien común: no matar, no robar, no levantar falso testimonio ni mentir, no codiciar los bienes ajenos, entre otros. Entonces, ¿qué diferencia tan esencialmente una moral "religiosa" de una moral "atea"?

Creo que los puntos básicos se refieren a su origen y a su finalidad. La conciencia colectiva de la institución religiosa -sistematizada por convenientes corpus doctrinarios, indiscutibles a partir de la Baja Edad Media, y por la difusión de la Vulgata Latina- necesita de una suprapotencia que reemplace a las estructuras naturales que la organización humana se ha venido dando desde el momento en que el ser humano se gregariza, esto es, que reemplace el gobierno de quienes fueron capaces de proteger a la comunidad y proveerla de sus necesidades básicas. Nietzsche señala que, en las primeras sociedades este grupo dominante era el que, junto con detentar el poder, daba las pautas de qué se iba a entender por moral; a su vez, atribuye el surgimiento de la moral religiosa a una progresiva hipervaloración de la mística de quienes habían sido excluidos de la comunidad que seguía estas pautas, con lo cual logran dominar su alma y así subyugar su voluntad. 
De hecho, al revisar el mismo Libro Sagrado del cristianismo, es posible observar que la propuesta del mismo Cristo no implica ninguna imposición, sino más bien una invitación, libre de prejuicios, libre de dogmas: recordemos que a los dogmáticos -los fariseos y escribas- los califica de "sepulcros blanqueados".

Pero vuelvo a la idea de este párrafo. La moral religiosa sólo puede actuar desde la perspectiva de la divinización de su origen, pues debe legitimarse como modelo alternativo al de la moral social o de la moral natural, que eran las perspectivas más ampliamente desarrolladas en nuestra sociedad occidental en sus inicios, eminentemente greco-latina. La relación de Dios con el Hombre, según lo plantea el mismo Nuevo Testamento, descansa en la unión íntima con el Creador, en el llamado personal y en la praxis reflexiva e introspectiva del espíritu.

En cuanto a las finalidades, éstas comienzan a distorsionarse, al menos formalmente, creemos, con la caída del Imperio Romano y la elevación del cristianismo a religión de Estado, en un nivel político caracterizado por no haber sido nunca partidario oficial de una moralidad en particular. En ese instante comienza la eliminación sistemática de pensamientos y constructos morales diversos, inclusive dentro del mismo cristianismo: gnósticos, arrianistas, cátaros, franciscanos, templarios y muchos otros cayeron bajo las redes de una institución que, a la manera del Opus Dei en la actualidad, sólo pudo prosperar atrayendo hacia sí un poder político que la cobijara. Desde ese momento, las normas que regularán la sociedad en el período oscuro de nuestra historia conocido como Edad Media, serán dictadas por el poder religioso, que no sólo llevará las riendas de los espíritus sino también de los maravedíes y de las armas.

Es más, si recordamos por un instante el fundamento de la moral cristiana en particular, ya que construye la perspectiva de la sociedad occidental, podremos darnos cuenta que la base de ésta se halla en lo punitivo: hay que comportarse de una determinada manera, de acuerdo al canon divino, para no 'enojar' a Dios 
Ateísmo y Laicismo: Nuevos horizontes para Chile - Manuel Contreras Seitz y Carlos Livacic Rojas

y condenarse en el Infierno, gran regalo de la teología al Hombre, o como dice Barker (2003).

La amenaza de la condenación está diseñada para ser un incentivo para las buenas acciones; pero es una falsa moral. Los humanistas pensamos que debemos hacer el bien por amor a la bondad, no por la egoísta perspectiva de cosechar recompensas individuales o evitar el castigo. Cualquier ideología que convence amenazando con la violencia es una ruina moral.

Si la única forma en que Ud. puede ser obligado a ser bueno con los demás es con la amenaza del infierno, ello muestra qué poco se valora Ud. mismo. Si la única manera en que puede motivársele a que sea bondadoso con los demás es la promesa del cielo, ello muestra cuán poco valora Ud. a los demás.

Creemos que aquí se encuentra, precisamente, el fundamento de la moral atea: su Humanismo explícito y su filosofía laica. Para ello son herramientas poderosas el uso de la razón y el ejercicio de la bondad. No se trata de relativizar los conceptos, sino de objetivarlos, puesto que se hace difícil pensar que habrá tantas morales 'correctas' como religiones existan sobre la faz de la tierra y, mucho más, suponer que la moral de una sola de ellas sea la única con validez plausible.

Para el ateo, entonces, ¿cuál sería el norte de su moral? Simplemente el evitar el daño innecesario. El daño es una acción natural en todo organismo y, por lo tanto, el evitarlo conlleva un ejercicio real y material de la voluntad. Como seres racionales, poseemos la capacidad para determinar sus causas y actuar sobre ellas. El solo hecho de luchar por evitar el dolor y mejorar la calidad de vida de quienes conforman nuestro entorno nos hace seres morales. Sin acción cósmica, sin recompensas futuras, sin castigos eternos, sin culpas colectivas que saldar. La moral atea es la base misma de la sociedad humana, ya que pone al ser humano como centro de su accionar, o lo que es lo mismo, se adentra en la naturaleza humana para preguntarse por su esencia, sus 
necesidades, por su entorno y por la manera en que actúa gregariamente, y así evitar el daño que pueda provocarse a otros seres humanos.

Esta es la base, también, del Humanismo: el ser humano, centro del accionar en la cadena evolutiva de la Naturaleza, preocupación esencial de las comunidades sociales y de los individuos que las conforman, motor de la justicia social, del bienestar común y de las libertades individuales. De allí que la moral atea sea necesariamente laica y humanista, basada en la razón, la bondad, la ley natural y los derechos humanos.

El ateo, en sociedad, desde el accionar positivo, sólo busca el bienestar de otros seres humanos desinteresadamente, sin motivación por una trascendente recompensa o castigo. Lo mueve sólo el convencimiento de que la justicia, la solidaridad y la igualdad de oportunidades son las herramientas para elevar la calidad de vida de sus congéneres y conseguir una mayor fraternidad entre los miembros de la raza humana, lo que implica, en último término, restituir los equilibrios con la Naturaleza y el Universo entero.

Parafraseando el título de un libro, la moral del ateo es una opción de conciencia y no una imposición de doctrina. La conciencia permite el libre ejercicio de la razón y el desarrollo del espíritu, en la búsqueda de la verdad y en la práctica de la bondad. La imposición doctrinaria impide la comprensión final de los objetivos de la moral promulgada, obliga al "acto de fe" y sujeta las voluntades a través del "terror místico"; el ejercicio de la moral se transforma, entonces, en una obligación impuesta que, como tal, es lícito evadir o violar cuando sea posible. Al contrario, al ser producto de la reflexión y de la convicción interior, es mucho más factible asentar sobre bases sólidas, de principios valóricos, el accionar cotidiano del individuo en su interacción social.

"El Dogma es una opinión o principio, publicado universalmente como incontrovertible e inapelable, cuyo desacato trae habitualmente 
Ateísmo y Laicismo: Nuevos horizontes para Chile - Manuel Contreras Seitz y Carlos Livacic Rojas

el terrible anatema que cierra para siempre al hereje, las puertas de la salvación. Es básicamente una creación del hombre, que en su soberbia pretende poseer las verdades más trascendentales venidas en forma directa de la divinidad; bajo su arbitrio, deben desaparecer las discusiones, manteniendo las materias en el dominio de la oscuridad, pues no acepta la discusión libre. El dogma, como bien ha sido demostrado a través de la historia, se ha valido de la ignorancia para conducir a los pueblos al dominio de lo sobrenatural, conduciéndola y subordinándola a sus propios terrenos" (Castaing et al., El Laicismo).

Hemos tratado de esbozar, brevemente, una reflexión sobre el concepto de ateísmo, además de referirnos al punto más cuestionado de esta forma de pensamiento: su postura axiológica. Sin embargo, no es posible dejar de lado otra etapa en este proceso de reflexión: ¿cómo se relaciona esta postura con un concepto de sociedad laica?

Si consideramos los conceptos expuestos anteriormente, podremos ver que una de las consecuencias naturales de la formulación del ateísmo es, precisamente, el laicismo, que significa desarrollar un modo de vida que no se apoye en ninguna revelación especial, sino que adhiera a los valores y verdades derivados de las artes, las ciencias, las filosofías y las religiones, no olvidando que es un hombre libre por su propia naturaleza.

Esto quiere decir que, en esencia, el laico es un hombre tolerante, seguidor de la moral común o natural y cuya espiritualidad queda resguardada en "aquella religión en la cual todos los hombres están de acuerdo", que representa para el ateo la expresión última de las leyes generatrices del Universo y de su funcionamiento.

Para el ateo, este concepto evoca el principio del orden regulador del mundo manifestado, es una creencia basada en la razón, que observa una religión natural, pero que rechaza la revelación y el dogma. Se le puede reconocer como principio creador, organizador del Universo y, por tanto, dinámico por excelencia; tam- 
bién es posible situarlo en la óptica de la ley que rige la materia, cuya manifestación sensible es lo percibido por el ser humano. Al insertarse en este orden de cosas, el ateo podrá contribuir con sus investigaciones y sus reflexiones a observar desde diversas ópticas los principios que rigen el Universo, tanto en el macrocosmos como en el microcosmos.

Pero retomemos el estado de la discusión. ¿Cómo relacionamos el concepto en discusión, el ateísmo, con el de una sociedad laica, amplia e inclusiva? Desde la perspectiva del ateísmo comprometido, la laicidad es el único fondo coherente posible para la organización política y social de la realidad. En claro tenemos que dejar aquí, entonces, que entendemos el laicismo no como un anticlericalismo, sino como la exigencia de una escrupulosa voluntad de preservar el espacio público frente a la apropiación del mismo que postula, de forma explícita o solapada, la ideología clerical. En este contexto la laicidad se revela como la garantía de la libertad de todos los ciudadanos a profesar sus propias convicciones, sean cuales sean, siempre que éstas sean capaces de respetar a todas las personas y sus derechos (Marset, 2002:55).

Esto es, para evitar caer en dogmatismos de cualquier especie -tanto clericales como anticlericales, religiosos o arreligiososes necesario garantizar un marco social que contribuya al desarrollo de la libertad de conciencia, como requisito sine qua non para constituir un sistema cognitivo que permee todas las acciones del ser humano. Dentro de esta óptica, entonces, se reconoce que no existe una verdad única, aunque individualmente pueda uno creer que la propia es la más plausible y sustentable, lo que trae como derivación el hecho que no se pueda imponer una visión de las cosas al resto de la sociedad, por cuanto se debe aceptar el carácter provisorio de las propias conclusiones y, en último término, respetar el principio básico de la libertad y validez privada de cualquier elección.

De aquí extrapolamos que, la dificultad existente para la coexistencia entre dos cosmovisiones diferentes como la laica y la 
Ateísmo y Laicismo: Nuevos horizontes para Chile - Manuel Contreras Seitz y Carlos Livacic Rojas

religiosa no radica en las formas que ellas tienen de observar la realidad, sino en la inherente tendencia del dogmatismo -de cualquier naturaleza- por transformar una opinión particular en tesis universal que debe ser superpuesta y aceptada por las demás. Cualquier ideología dogmática no aspira a que sus miembros vivan su proyecto de vida, sino que pretende instaurarla en el mundo, imponerla al resto de la sociedad e inducir a la clericalización de la vida política y social. Para muestra, un botón: recuérdese una famosa declaración del Cardenal chileno Francisco Javier Errázuriz, señalando que los parlamentarios católicos que votasen a favor de la "ley de divorcio" quedarían automáticamente excomulgados. Recuerdo una frase de los Evangelios, cuando ciertos fariseos, tratando de que Jesús se auto inculpara de algún delito grave para poder condenarlo, le preguntaron por los tributos que debían pagar a Roma. El Cristo, tomando una moneda y señalando sus inscripciones respondió: "Dad al César lo que es del César, y a Dios, lo que es de Dios". Dios no es el César, ni el César es Dios. Claridad confundida a través de los tiempos.

¿Por qué se suceden estas situaciones? Pues porque para el integrismo la libertad personal, en los hechos, no existe, aun cuando se proclame un pseudo "libre albedrío", ya que en la práctica no se reconoce ni la responsabilidad ni la capacidad de análisis crítico, por cuanto sólo hay una verdad a la que hay que reconocer, un dogma que seguir, una autoridad que obedecer y, por ende, un solo camino a la "salvación". Esto nos conduce al siguiente estado de cosas: quien está investido por una autoridad superior, en el sentido trascendental-divino, considera que sus conceptos y opiniones tienen más valor, justamente porque no proceden ni de la libertad ni de la igualdad, sino que se poseen en virtud de una "representación" terrenal de una entidad trascendente que le otorga el conocimiento de la verdad. Esto ha llevado a que todas las religiones organizadas, y también todo tipo de ideologías, se vinculen con el poder político para imponer sus doctrinas y defender sus intereses. 
Es por ello que en el marco de la laicidad se hace de necesidad extrema el construir un modelo de organización social capaz de garantizar la libertad de conciencia ciudadana, manteniendo de este modo el ámbito de las opiniones dentro de los límites de la individualidad. La laicidad es, entonces, un espacio de oposición a la identificación del poder político con cualquier ideología, ya que garantiza la libertad de todos los individuos a profesar sus propias convicciones, en el marco del respeto con los demás y con sus derechos. El concepto de una sociedad laica radica en la pluralidad y la democracia, o como dice Marset (2002:71):

La pluralidad deriva de la aceptación de la libertad de conciencia y de la igualdad de derechos, y es un eficaz instrumento para ordenar las relaciones sociales entre individuos con ideas diferentes pero igualmente legítimas. Para ello el único requisito necesario debe ser el reconocimiento de la tolerancia entendida como "respeto" a la diferencia, como aceptación del hecho diferencial que además de ser plenamente legítimo debe contribuir a enriquecer el debate social, no como algo que hay que "sufrir" para hacer soportable la convivencia. Para lograr una sociedad verdaderamente plural es preciso potenciar el sentido de cooperación desde la discrepancia frente a la estrategia de confrontación encaminada a servirse de la tolerancia para imponer la hegemonía de la intransigencia. La pluralidad debe concebirse como colaboración que permita incluir a todos con sus peculiaridades y que les ayude a progresar juntos sin exclusiones, pese a sus divergencias, en beneficio de toda la colectividad.

En este sentido es que el laicismo define la autonomía del Estado, y de los poderes públicos en general, de cualquier iglesia o credo, dominante o no, o de cualquier grupo de interés particular; con todo, garantiza igualmente la autonomía en la esfera privada de todos los ciudadanos, sea cual fuere su concepción filosófica o religiosa. El Estado y sus poderes públicos aspiran al bien común de todos los ciudadanos. Ningún grupo puede, en nombre de un principio trascendente, de un texto sagrado, de 
Ateísmo y Laicismo: Nuevos horizontes para Chile - Manuel Contreras Seitz y Carlos Livacic Rojas

una iglesia, de una ideología o de una filosofía, pretender apropiarse de aquél.

En todo caso, la laicidad de Estado es una concepción no agresiva a la cual pueden aspirar los creyentes de no importa cuál religión, así como los no creyentes. Valores tales como la democracia y los derechos del hombre constituyen un común denominador importante entre la sociedad civil y la laicidad organizada.

Creemos que para Chile, hoy en día, esta es una aspiración legítima que aún tiene real vigencia, ya que las sensibilidades sociales están preparando cambios importantes en la conducta social efectiva, más que en la opinión declarada, aunque hemos visto, cada vez más, que se están perdiendo los miedos, y la libertad de opinión, así como la de conciencia, es cada vez más difícil de acallar.

A esa libertad es a la que queremos apelar. No a la irreflexión ni al apasionamiento, sino al libre examen y a la propia convicción de las ideas. Una vez que nuestra sociedad haya madurado estos procesos, estaremos en condiciones de tener claridad en el ideal ciudadano al que aspiramos, así como conjugar valores aceptados por la mayoría pero combatidos por algunos y que, por desgracia, hoy tienen mayor valoración en las fuerzas políticas, debido a los ejes de interés que las circundan.

\section{Bibliografía}

Barker, Dan (2003). “CCómo puede un ateo ser moral?”, en www.ffrf.org/ articles/bondad.html.

Bessa, Cassiano (2003). “Uma introdução ao Ateísmo”, en www.ateismo. net.

Castaing, Humberto; Mario Mohr, Rubén Molina y Jorge Zepeda (2006). “El Laicismo", en ISIS, Año II, No 4, Osorno, pp. 53-67.

Drange, Theodore M. (1998). "Atheism, agnosticism, noncognitivism”, en www.infidels.org/ library/modern/theodore_drange/definition.html 
García Valenzuela (1997). Introducción a la historia de la Francmasonería en Chi$l e, 2^{a}$ edición, Gran Logia de Chile, Santiago.

Gran Logia de Chile (2002). Temas valóricos: ¿Opción de conciencia o imposición de doctrina? Recuento de una polémica, Club de la República, Santiago.

García Alonso, Luz (1997). "Moral -absoluta y trascendente- y morales", en Logos, septiembre-diciembre, Hemeroteca Virtual ANUIES, Asociación Nacional de Universidades e Instituciones de Educación Superior, www.hemerodigital.unam.mx/ANUIES.

Gorrón, Eduardo (2003). "La relación Dios-Ética ¿Son Dios y la moral inseparables?", en Idea Sapiens, www.ideasapiens.com/religion/ relacion\%20Dios-etica.htm.

Grollet, Philippe; Georges Liénard, Chanoine Pierre de Locht y Edouard Delruelle (1999). Questions sur la laïcité; Outils de Réflexion $\mathrm{N}^{\circ}$ 08, Centre D'Action Laïque, Bruxelles.

Haarscher, Guy (2002). El Laicismo, Instituto Laico de Estudios Contemporáneos (ILEC), Santiago.

Hurtado, Alberto (1941). ¿Es Chile un país católico?, Splendor, Santiago.

Marset, Joan Carles (2002). "Ateísmo y laicidad", en Laicidad y derecho al espacio público. II Encuentro por la laicidad en España, Vicenç Molina (coord.), Eds. Gráficas Rey, Barcelona; pp. 55-77.

Nietzsche, Federico (1999). Más allá del bien y del mal, Folio, Navarra.

Ortega, Miguel (1981). El Cardenal nos ha dicho. 1961-1982, Salesiana, Santiago.

Real Academia Española (1995). Diccionario de la Lengua Española, edición electrónica, versión 21.1.0, Espasa-Calpe, S.A., Madrid.

Scheinin, Richard (1993). "Y no lo que yo predico", en San José Mercury Newws, extractado de www.angelfire.com/az/ateismo/moralidad.html. 